\title{
Minority Top Talent Training Demand Analysis for Common University Take Guizhou University of Finance and Economics as an Example
}

\author{
Bo-wen Zhang ${ }^{1}$, Shi-hua $\mathrm{XU}^{2 *}$, Chun-hong Duan ${ }^{3}$ \\ ${ }^{1)}$ Western Modernization Research Center, GuiZhou University of F\&E, Guiyang, Guizhou, China, 550025 (zbwmjr@ 163.com) \\ ${ }^{2)}$ YouJiang Medical University for Nationalities, Baise, Guangxi, China, $533000 *$ (xushihua28@yahoo.com.cn) \\ ${ }^{3)}$ School of Education Administration, GuiZhou University of F\&E, Guiyang, Guizhou, China (chunhduan@163.com)
}

\begin{abstract}
Accelerating minority top talent's training is the urgent request of accelerating minority region's economic and social development and achieving goal of fully constructing well-off society. For common university, it is necessary to expand the function of minority higher education, in order to train top talent to meet the demand of minority region. After all, different from university for nationalities, common university is not focus on training minority cadres or professional technical talents. In order to further expand the function of minority higher education, we need to combine the necessity of minority top talent's training and the feasibility of professional discipline's development, empirically analyze the actual demand. Then accordingly adjust professional discipline's layout and personnel training goal, build corresponding minority top talent training mode.
\end{abstract}

Keywords - common university, minority top talent, personnel training, necessity, feasibility, demand

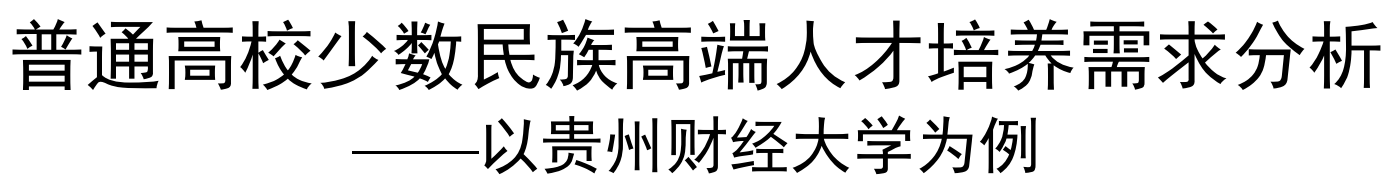

\author{
张博文 $^{1} \quad$ 许世华 ${ }^{2 *}$ 段春红 $^{3}$ \\ 1) 贵州财经大学西部现代化研究中心, 贵阳, 贵州, 中国 \\ 2) 右江民族医学院，百色，广西，中国 \\ 3)贵州财经大学教育管理学院, 贵阳, 贵州, 中国
}

摘 要 加强少数民族高端人才培养是加快民族地区经济社会发展步伐、实现全面建设小康社会奋斗目标的迫切要求。对于普通 高校来说, 培养少数民族地区经济社会发展极度贵乏的高端人才, 有必要拓展民族高等教育办学功能。毕竟, 普通高校区别于民族院 校, 不是以培养民族干部或专业技术人才为办学重点, 要进一步拓展民族高等教育办学功能, 就必须将少数民族高端人才培养的必要 性与自身学科专业发展的可能性结合起来, 对人才培养现实需求进行实证分析, 并据此调整学科专业布局和人才培养目标, 构建相应 的少数民族高端人才培养模式。

关键词 普通高校, 少数民族高端人才, 人才培养, 必要性, 可行性, 需求

基金项目: 全国教育科学 “十一五” 规划 2010 年度单位资助教育部规划课题 (FFB108160); 贵州省首届教育科学规划重点课题 (2013A085); 贵州财经大学引进人才科研启动项目

作者简介: 张博文(1970- ), 男, 河南博爱人, 贵州省高等学校人文社会科学研究基地贵州财经大学中国西部现代化发展研究中心, 副主任, 教授, 博士, 研究方向为院校研究、高等教育管理、教育发展与人的现代化, 邮箱 zbwmjr@ 163.com, 手机 13027830146。

段春红(1982- ），四川西昌人，硕士，研究方向为教育信息化，邮箱 chunhduan@163.com，手机 13893973529

*通讯作者: 许世华(1976- ), 男, 湖北荆州人, 右江民族医学院副研究员, 硕士, 研究方向为高等教育管理, 邮箱 13036969626@163.com,

手机 18907764868。通讯地址: 广西百色市城乡路 98 号, 邮编: 533099 
所谓少数民族高端人才, 是指热爱本民族、能够领导 和服务科学发展, 且为民族地区经济社会建设做出较大贡 献的各类民族干部或专业技术人员的总称。加强少数民族 高端人才培养是加快民族地区经济社会发展步伐、实现全 面建设小康社会奋斗目标的迫切要求。对于普通高校来说, 培养少数民族地区经济社会发展极度贵乏的高端人才，有 必要进一步拓展民族高等教育办学功能。为此, 必须从少 数民族地区经济社会发展的迫切要求和学校自身学科专业 发展的可能性两个方面, 对普通高校少数民族高端人才培 养的必要性、可行性进行具体分析, 准确把握少数民族地 区经济社会发展对于高端人才培养的现实需求。只有这样, 才能对普通高校学科专业布局和人才培养目标加以调整, 从而构建相应的少数民族高端人才培养模式, 将加强少数 民族高端人才培养、进一步拓展民族高等教育办学功能落 到实处。这里, 我们就以贵州省普通高校为研究对象、以 贵州财经大学为研究个案, 对贵州省少数民族高端人才培 养的现实需求进行具体。

\section{1. 普通高校少数民族高端人才培养的必要性}

贵州属于我国八个民族省份之一, 少数民族占全省总 人口 $37.9 \%$, 民族自治地方占全省总面积 $55.5 \%$, 是全国贫 困问题突出的欠发达省份。对于贵州来说, 实现后发赶超,
人才是关键。当前, 实现全面建设小康社会的奋斗目标, 必须加快民族地区经济社会发展步伐。为此, 必须充分利 用各种民族教育资源, 尤其是拓展普通高校民族教育办学 功能, 培养大批少数民族高端人才, 尽快解决人才问题。

\section{1 贵州少数民族人才现状与需求预测}

贵州简称“黔”或“贵”, 辖 6 个地级市、3 个自治州, 共 有 88 个县(市、区、特区), 国土面积 17.6 万平方公里, 是 一个少数民族大杂居、小聚居的省份。[1]少数民族地区主 要包括黔东南苗族侗族自治州、黔南布依族苗族自治州、 黔西南布依族苗族自治州 3 个自治州、11 个自治县、 254 个民族乡。根据 2010 年第六次人口普查, 贵州少数民族常 住人口 1254.80 万人, 占全省常住人口的 $36.11 \%$, 同 2000 年第五次人口相比下降 $2.24 \%$; 人口超过 10 万的少数民族 从多到少依次为苗族、布依族、土家族、侗族、彝族、仡 佬族、水族、回族、白族。[2]

\subsection{1 贵州少数民族人才建设现状}

近年来, 贵州省委组织部和人力资源社会保障厅对全 省人才资源建设尤其是少数民族人才建设情况进行了多次 比较详尽的调研。根据最新人才建设调研报告, 贵州少数 民族人才基本情况如表 1 所示。

表 1 贵州省少数民族人才基本情况（2012）

\begin{tabular}{|c|c|c|c|}
\hline 人才类别 & $\begin{array}{l}\text { 少数民族人才现有量 } \\
\text { (占该类比重) [3] }\end{array}$ & 全省人才现有量（学历比例） [4] & $\begin{array}{l}\text { 《贵州省中长期人才发展规划纲要 } \\
\text { (2010 2020 年)》2020 年目标 [5] }\end{array}$ \\
\hline 党政人才 & $74059(39.7 \%)$ & $\begin{array}{l}186515 \text { (研究生 } 3 \% \text { 、本科 } 52.2 \% \text { 、专科 } 38.3 \% \text { 、 } \\
\text { 中专及以下 } 6.5 \% \text { ) }\end{array}$ & 20 万, 本科及以上学历的占 $85 \%$ \\
\hline $\begin{array}{l}\text { 企业经营管理 } \\
\text { 人才 }\end{array}$ & $67361(15.4 \%)$ & $\begin{array}{l}436196 \text { (研究生 } 0.9 \% \text { 、本科 } 22.5 \% \text { 、专科 } \\
31.6 \% \text { 、中专及以下 } 45 \% \text { ) }\end{array}$ & $\begin{array}{l}35 \text { 万, 新任职国有企业领导人员通过竞争 } \\
\text { 选聘的比例达 } 50 \% \text { 以上 }\end{array}$ \\
\hline 专业技术人才 & $315291(37.4 \%)$ & $\begin{array}{l}842020 \text { (研究生 } 2.1 \% \text { 、本科 } 40.1 \% \text { 、专科 } \\
46.1 \% \text { 、中专及以下 } 11.7 \% \text { ) }\end{array}$ & $\begin{array}{l}105 \text { 万, 高级、中级、初中比例达 10: 40: } \\
50\end{array}$ \\
\hline 技能人才 & $145494(19.6 \%)$ & $\begin{array}{l}\text { 743417(研究生 } 0.1 \% \text { 、本科 } 5.1 \% \text { 、专科 } 16.3 \% \text { 、 } \\
\text { 中专及以下 } 78.3 \% \text { ) }\end{array}$ & 90 万, 高技能人才占 $27.78 \%$ \\
\hline 农村实用人才 & $228165(35.9 \%)$ & $\begin{array}{l}635211 \text { (本科 } 0.4 \% \text { 、专科 } 2.2 \% \text { 、中专及以下 } \\
97.4 \% \text { ) }\end{array}$ & $\begin{array}{l}60 \text { 万, 每个行政村主要特色产业有 } 2 \text { 名以 } \\
\text { 上示范带动能力强的带头人 }\end{array}$ \\
\hline 社会工作人才 & 起步晚, 很少 & 起步晚, 很少 & 8 万左右, 强调人才的职业化和专业化水平 \\
\hline
\end{tabular}

由上表可以看出, 全省党政人才、专业技术人才、技 能人才、社会工作人才现有量与规划量相比, 均有较大缺 口; 缺口绝对数量最大的是专业技术人才, 缺口 21 万, 其 次是技能人才和社会工作人才, 党政人才和企业经营管理 人才虽然绝对数量与规划数量相差不大、甚至略有超过, 但学历结构偏低、高端人才需求上的缺口仍然较大, 农村 实用人才中高端人才的比例也很低、缺口不小。再从少数
民族人才所占比例来看, 党政人才、专业技术人才和农村 实用人才均比较高, 基本达到或甚至超过少数民族人口所 占比例 $36.11 \%$; 相比之下, 企业经营管理人才和技能人才 所占比例较低。目前看来, 尽快缩小少数民族人才现有量 和需求量之间的差距, 是有很大难度的。究其原因, 主要 是因为少数民族人才队伍学历难以达到规定的要求。毕竟, 民族地区由于经济发展缓慢、教育滞后、思想观念落后、 
人才开发环境和人事管理体制有待优化等原因上大学的人 数比较少, 文化程度和受教育程度低。[6]

\subsection{2 贵州少数民族人才需求预测}

按照贵州省民委规划, 贵州“十二五”少数民族队伍建 设主要有 3 个方面。[7]一是实施少数民族人才培养工程。 加强少数民族干部和高层次创新人才的培养和选拔, 重点 培养少数民族专家学者、少数民族妇女干部、少数民族企 业经营管理者和青年科技干部, 推进少数民族地区与其他 地区干部人才的交流, 选派一定数量的少数民族干部到中 央国家机关和经济相对发达地区挂职锻炼。二是少数民族 技能人才队伍建设。采取多种形式继续加大民族地区技能 人才培训力度, 进一步加强少数民族艺术人才培训。在民 族自治地方开班民族技师班, 实施“新技师培养计划”, 建 设培养以高级工、高技能为重点的工种配套、结构合理的 少数民族技能人才队伍; 建设少数民族技能培训基地, 培 养少数民族非物质文化遗产保护和传承的特殊技能人才; 开展城乡少数民族妇女创业培训。三是少数民族农村实用 人才队伍建设。围绕解决“三农”问题的需要, 培养民族地 区农业科技人员、少数民族农村乡土人才、少数民族农村 能够巧匠和新型农民、创业带头人，进一步提高民族地区 广大农村群众的整体素质。另外, 少数民族人才培养工程 主要有 2 项, 一项是少数民族人才培养推进计划, 即安排 一定专项资金, 五年共培养少数民族党政人才 2000 名, 少 数民族企业经营管理人才 500 名, 少数民族专业技术人才 1000 名, 少数民族特殊技能人才 1000 名, 少数民族农村 实用人才 10000 名, 少数民族社会工作人才 500 名, 各类“双 语” 人才 1500 名。另外一项是少数民族人才 “ 312 ”工程, 每 年在“三支队伍”人才培训中安排培训少数民族人才 3000 名 左右, 选送优秀中青年少数民族人才 100 名赴国内重点高
校培训学习、 20 名左右赴国外进修深造。具体少数民族人 才需求情况如表 2 所示。

表 2 贵州少数民族人才需求情况

\begin{tabular}{|c|c|c|}
\hline 序号 & 人才分类 & 重点 \\
\hline 1 & 少数民族党政人才 & $\begin{array}{l}\text { 少数民族干部, 重点培养少数民族 } \\
\text { 妇女干部、青年科技干部 }\end{array}$ \\
\hline 2 & $\begin{array}{l}\text { 少数民族企业经营 } \\
\text { 管理人才 }\end{array}$ & 少数民族企业经营管理者 \\
\hline 3 & $\begin{array}{l}\text { 少数民族专业技术 } \\
\text { 人才 }\end{array}$ & \\
\hline 4 & 少数民族技能人才 & $\begin{array}{l}\text { 少数民族艺术人才、少数民族非物 } \\
\text { 质文化遗产保护和传承的特殊技能 } \\
\text { 人才、城乡少数民族妇女创业人才 }\end{array}$ \\
\hline 5 & $\begin{array}{l}\text { 少数民族农村实用 } \\
\text { 人才 }\end{array}$ & $\begin{array}{l}\text { 民族地区农业科技人员、少数民族 } \\
\text { 农村乡土人才、少数民族农村能工 } \\
\text { 巧匠、新型农民、创业带头人 }\end{array}$ \\
\hline 6 & $\begin{array}{l}\text { 少数民族社会工作 } \\
\text { 人才 }\end{array}$ & \\
\hline 7 & 其他 & $\begin{array}{l}\text { 高层次创新人才（少数民族专家学 } \\
\text { 者)、各类“双语”人才 }\end{array}$ \\
\hline
\end{tabular}

1.2 贵州民族院校与少数民族人才培养现状

贵州现有民族院校 8 所, 少数民族人才培养主要集中 在师范、医药卫生等社会发展领域。目前, 在 8 所民族院 校中, 贵州民族大学是贵州民族高等教育的中坚力量, 全 日制在校生 21700 多人，少数民族学生和来自民族地区、 西部地区的学生占 $80 \%$ 以上, 其省级特色和重点学科为民 族学、数学、法学、新闻传播学、中国少数民族语言文学、 数学与应用数学、社会学、马克思主义基本原理。具体贵 州民族院校和少数民族人才培养情况如表 3 所示。

表 3 贵州民族院校和少数民族人才培养情况 [8]

\begin{tabular}{|c|c|c|c|c|}
\hline 序号 & 学校名称 & \begin{tabular}{|l|} 
办学层次 \\
\end{tabular} & 办学规模 & 办学定位 \\
\hline 1 & 贵州民族大学 & 本科 & 在校生 21700 多人 & 人文科学、社会科学、理学为主 \\
\hline 2 & 兴义民族师范学院 & 本科 & 在校生近 8083 人 & 师范为主 \\
\hline 3 & 黔南民族师范学院 & 本科 & 在校生 13000 余人 & 师范为主 \\
\hline 4 & 黔南民族医学高等专科学校 & 专科 & 在校专科生 5197 人 & 医药卫生为主 \\
\hline 5 & 黔东南民族职业技术学院 & 专科 & $\begin{array}{l}\text { 在校生近 } 1.5 \text { 万人, 含高 } \\
\text { 职生 } 9500 \text { 余人 }\end{array}$ & $\begin{array}{l}\text { 护理、临床医学、药学、口腔医学、会计、园林、 } \\
\text { 建筑工程技术、汽车检测与维修技术等 }\end{array}$ \\
\hline 6 & 黔南民族职业技术学院 & 专科 & $\begin{array}{l}\text { 以 } 4000 \text { 人在校生规模为 } \\
\text { 基础 }\end{array}$ & $\begin{array}{l}\text { 设管理系(旅游经济系)、财经系、机电工程系、生 } \\
\text { 物工程系、计算机科学系 }\end{array}$ \\
\hline 7 & 黔西南民族职业技术学院 & 专科 & 在校生 7200 余人 & $\begin{array}{l}\text { 设生物工程系、机械与电子工程系、水利电力工程 } \\
\text { 系、商务系、医药系 } \\
\end{array}$ \\
\hline 8 & 贵阳医学院神奇民族医药学院 [9] & 本科 & 在校生 5300 人 & 以医为主 \\
\hline
\end{tabular}

（数据来源：各高校网站） 
由上表可以看出, 目前贵州各民族院校在校本科生为 42800 人左右、在校专科生为 36600 人左右, 每年人才培 养规模大约 23000 人。如此人才培养规模和培养能力, 显 然与《贵州省中长期人才发展规划纲要（2010 2020 年)》 中关于本科及以上学历占 $85 \%$ 和高技能人才比例的要求相 差甚远, 且与贵州“十二五”少数民族队伍建设规划中人才 需求重点也有很大差距。

综上所述, 面对贵州少数民族高端人才巨大的需求缺 口，仅靠现有贵州民族院校培养少数民族高端人才是难以 胜任的。从贵州省高校和人才培养的实际情况看, 加强少 数民族高端人才培养, 不仅有利于帮助民族地区加快经济 社会发展步伐、尽快实现全面建设小康社会的奋斗目标, 而且也是拓展普通高校社会服务职能、培养面向基层和地 方经济社会发展实际需要的高素质创新型人才的必然要 求。因此, 对于贵州省高校来说, 有必要加强少数民族高 端人才培养, 进一步拓展民族教育办学功能。

\section{2. 普通高校少数民族高端人才培养的可行性}

普通高校区别于民族院校，不是以培养民族干部或专 业技术人才为办学重点, 要进一步拓展民族高等教育办学 功能, 就必须将少数民族高端人才培养的必要性与自身学 科专业发展的可能性结合起来, 对学科专业布局和人才培 养目标进行局部调整。为此, 应立足学校办学定位和办学 条件, 从培育办学特色、谋求特色化办学的战略高度, 科
学筹划学校发展, 进一步优化学科专业结构。[10]对于贵州 财经大学来说, 也只有将少数民族高端人才培养的需求与 自身学科专业发展结合起来, 适当调整学科专业布局和人 才培养目标, 构建相应的少数民族高端人才培养模式, 才 能切实加强少数民族高端人才培养、拓展民族教育办学功 能。

2.1 贵州财经大学学科专业布局与少数民族高端人才培养 的关联度

贵州财经大学位于贵阳市, 拥有河滨、鹿冲关和花溪 三个校区, 总面积 5106.8 亩, 花溪主校区总建筑面积 55 万平方米，总投资 22 亿元，现有在校本科生 25000 余人, 研究生 1000 人。学校是一所以经济学、管理学为主体, 法 学、文学、理学、工学、教育学等多学科协调发展的综合 性财经类大学。现有 17 个二级学院, 51 个本科专业（方 向），6 个教育部特色专业，9个省级示范专业; 有 7 个一 级学科硕士学位授权点, 48 个二级学科硕士点, 5 个专业 学位硕士点; 有 7 个省级重点学科、16 个校级重点学科、 8 个校级重点扶持学科, 6 个省级科研机构或研究基地; 有 1 个国家级经济管理类实验教学示范中心, 1 个国家级人才 培养模式创新实验区, 2 个省级实验教学示范中心。[11] 其现有学科专业分布和专业建设情况如表 4、表 5 所示。

表 4 贵州财经大学现有本科专业分布（2013）

\begin{tabular}{|c|c|c|c|}
\hline 所在分院 & 专业 & 所在分院 & 专业 \\
\hline 经济学院 & 经济学 & 资源与环境管理学院 & $\begin{array}{l}\text { 资源与环境经济学、自然地理与资源环 } \\
\text { 境、人文地理与城乡规划、农林经济管 } \\
\text { 埋、土地资源管理、农村区域发展 }\end{array}$ \\
\hline 国际经济学院 & 国际经济与贸易、投资学、国际商务 & 教育管理学院 & 教育技术学、应用心理学 \\
\hline $\begin{array}{l}\text { 财政与税收 } \\
\text { 学院 }\end{array}$ & 财政学、税收学 & 信息学院 & $\begin{array}{l}\text { 计算机科学与技术、软件工程、信息管 } \\
\text { 与理与信息系统、电子商务 }\end{array}$ \\
\hline 金融学院 & 金融学、保险、金融工程 & 文化传播学院 & $\begin{array}{l}\text { 汉语言文学、汉语国际教育、广告学、 } \\
\text { 传播学 }\end{array}$ \\
\hline 工商管理学院 & 工商管理、市场营销、人力资源管理、物流管理 & 法学院 & 法学 \\
\hline 旅游管理学院 & 旅游管理、酒店管理 & 数学与统计学院 & 数学与应用数学、统计学 \\
\hline 会计学院 & 会计学、财务管理、审计学 & 外国语学院 & 英语、商务英语、日语 \\
\hline $\begin{array}{l}\text { 管理科学与工程 } \\
\text { 管理学院 }\end{array}$ & $\begin{array}{l}\text { 管理科学、工程管理、工程造价、房地产开发与管 } \\
\text { 理 }\end{array}$ & 艺术学院 & 音乐学、舞蹈学、环境设计 \\
\hline 公共管理学院 & $\begin{array}{l}\text { 行政管理、公共事业管理、劳动与社会保障、社会 } \\
\text { 工作 }\end{array}$ & & \\
\hline
\end{tabular}

资料来源: 《贵州财经大学本科培养方案(2013)》 
由上表可以看出, 目前学科布局是以经济学、管理学 为主体的, 分别达到 5 个学院和 4 个学院, 还跨了多个其 他学院。相对来说, 法学、文学、理学、工学、艺术学、 教育学涉及的学院相对单一, 但也比较灵活, 容易与学校 的主体学科相互融合, 形成各自学科发展的比较优势和特 色。上述学科, 无论是主体学科, 还是特色学科, 都与民 族地区经济社会发展联系比较紧密, 在少数民族高端人才 培养方面具有一定的发展潜力。

再从专业建设水平看, 目前所拥有的 6 个教育部特色 专业、9 个省级示范专业和 4 个省级特色专业, 更是为加 强少数民族高端人才培养、拓展民族教育办学功能提供了 诸多便利条件。具体特色优势本科专业见表 5 。

表 5 贵州财经大学优势本科专业（2013）

\begin{tabular}{|c|l|}
\hline 级别 & \multicolumn{1}{|c|}{ 专业名称 } \\
\hline $\begin{array}{c}\text { 教育部特色专 } \\
\text { 业 }(6 \text { 个 })\end{array}$ & $\begin{array}{l}\text { 旅游管理、会计学、农村区域发展、金融 } \\
\text { 学、市场营销、工程管理 }\end{array}$ \\
\hline $\begin{array}{c}\text { 省级示范专业 } \\
(9 \text { 个 })\end{array}$ & $\begin{array}{l}\text { 财政学、金融学、统计学、信息管理与信 } \\
\text { 息系统、市场营销、会计学、 } \\
\text { 财务管理、人力资源管理、旅游管理 }\end{array}$ \\
\hline $\begin{array}{c}\text { 省级特色专业 } \\
(4 \text { 个 })\end{array}$ & $\begin{array}{l}\text { 统计学、财务管理、劳动与社会保障、电 } \\
\text { 子商务 }\end{array}$ \\
\hline
\end{tabular}

由上表可以看出, 目前专业建设水平比较高的旅游管 理、会计学、农村区域发展、金融学、市场营销、工程管 理等 6 个教育部特色专业学科, 都与贵州“十二五”少数民 族队伍建设规划中人才需求重点有着较大的契合度。至于 财政学、金融学、统计学、信息管理与信息系统、财务管 理、人力资源管理等省级示范专业和劳动与社会保障、电 子商务等省级特色专业, 也与贵州 “十二五” 少数民族队伍 建设规划中人才需求重点密切相关。
2.2 贵州财经大学学科专业发展与少数民族高端人才培养 的可能性

相对而言, 贵州财经大学在加强少数民族高端人才培 养、拓展民族教育办学功能方面不仅潜力巨大, 而且调整 学科专业布局和人才培养目标的难度也不大, 只需要略微 调整一下人才培养的服务面向、更多地强调为少数民族地 区经济社会发展服务, 并据此确立少数民族高端人才培养 的目标定位、构建相应的少数民族高端人才培养模式。具 体说来, 应充分发挥现有学科专业优势, 将少数民族高端 人才培养聚焦于企业经营管理人才和社会服务人才, 使民 族教育的办学重点放在领导和服务民族地区的科学发展 上。

首先, 要大力培养少数民族企业经营管理类高端人才。 贵州民族地区多处于武陵山区、乌蒙山区等集中连片贫困 区, 民营经济发展非常薄弱。尽管目前企业经营管理人才 绝对数量较多, 但其学历结构中 $45 \%$ 为中专及以下, 少数 民族高端人才数量仍然匮乏。贵州财经大学以经济学、管 理学学科为主体, 是省委、省政府重点建设的贵州经济管 理人才培养基地, 其学科发展目标为做强经管学科、做实 法文学科、做特理工学科, 拥有培养少数民族企业经营管 理类高端人才的优势学科、科研机构、实验教学示范中心 和创新实验区等环境。大力培养少数民族企业经营管理类 高端人才，有利于促进贵州集中连片贫困区民营经济的发 展, 有利于提高民族地区人民生活水平, 有利于促进贵州 与全国同步实现小康。同时, 大力培养少数民族企业经营 管理类高端人才, 也符合学校以本科教育为主、积极发展 研究生教育和创办有特色高水平财经大学的办学定位, 符 合学校服务贵州经济社会发展、为贵州经济社会又好又快 发展提供高层次专业人才和智力支持的服务定位, 有利于 发挥学校办学优势, 突出学校办学特色, 打造学校企业经 营管理类高端人才培养品牌。具体少数民族企业经营管理 类高端人才培养的专业情况见表 6 。

表 6 贵州财经大学少数民族企业经营管理类高端人才培养的专业情况

\begin{tabular}{|c|c|c|c|}
\hline 专业名称 & 所在分院 & 专业名称 & 所在分院 \\
\hline 经济学 & 经济学院 & 会计学、财务管理、审计学 & 会计学院 \\
\hline 投资学 & 国际经济学院 & 广告学 & 文化传播学院 \\
\hline 财政学、税收学 & 财政与税收学院 & 商务英语 & 外国语学院 \\
\hline 金融学、保险、金融工程 & 金融学院 & 信息管理与信息系统、电子商务 & 信息学院 \\
\hline 工商管理、市场营销、 & 工商管理学院 & 管理科学、工程管理、工程造价 & 管理科学与工程管理学院 \\
\hline 人力资源管理、物流管理 & 旅游管理学院 & & \\
\hline 旅游管理、酒店管理 & & & \\
\hline
\end{tabular}


其次, 要大力培养少数民族社会服务类高端人才。贵 州少数民族高端人才培养除了企业经营管理类人才需求 外, 其他社会发展领域服务性人才也亟需引起关注。贵州 财经大学的法学、文学、理学、工学、教育学多学科协调 发展, 亦为少数民族社会服务类高端人才培养提供了现实 可能性。目前, 就电子信息、文化旅游、金融外贸、现代
物流经济发展领域和教育卫生、宣传文化、社会保障社会 发展领域, 可以在不影响学校整体办学格局的前提下适当 调整人才培养目标、课程体系和培养路径, 以适应少数民 族社会服务类高端人才培养的实际需要。具体少数民族社 会服务类高端人才培养的专业情况见表 7 。

表 7 贵州财经大学少数民族社会服务类高端人才培养的专业情况

\begin{tabular}{|c|l|l|c|}
\hline 服务领域 & 需求分类 & \multicolumn{1}{|c|}{ 专业 } & \multicolumn{1}{c|}{ 所在分院 } \\
\hline \multirow{4}{*}{$\begin{array}{c}\text { 经济发展领 } \\
\text { 域 }\end{array}$} & 电子信息 & 计算机科学与技术、软件工程、信息管理与信息系统、电子商务 & 信息学院 \\
\cline { 2 - 4 } & 文化旅游 & 旅游管理、酒店管理 & 旅游管理学院 \\
\cline { 2 - 4 } & 金融外贸 & 金融学、保险、金融工程 & 金融学院 \\
\cline { 2 - 4 } & 国际经济与贸易、投资学、国际商务 & 国际经济学院 \\
\cline { 2 - 4 } & 现代物流 & 工商管理、市场营销、人力资源管理、物流管理 & 教育管理学院 \\
\hline \multirow{3}{*}{$\begin{array}{c}\text { 社会发展领 } \\
\text { 域 }\end{array}$} & 教育卫生 & 教育技术学、应用心理学 & 文化传播学院 \\
\cline { 2 - 4 } & 宣传文化 & 汉语言文学、广告学、传播学 & 公共管理学院 \\
\cline { 2 - 4 } & 社会保障 & 行政管理、公共事业管理、劳动与社会保障、社会工作 & \\
\hline
\end{tabular}

\section{参考文献(References)}

[1] Guizhou Province's Goverment Website. Guizhou eneralSituation.http://info.gzgov.gov.cn/system/2013/06/18/0123 85008.shtml.2013.06.

[2] Mou-li Tao, Xin-wu Zhu, Sai-mei Zhong. Guizhou Statistical Yearbook (2013). Beijing: China Statistics Press.2013.09:39-40.

[3] Jie Yu, Da-hua Wu, Annual Report on Talent Development of Guizhou (2013). Beijing: Social Science Document Press. 2014.03: 12 .

[4] Jie Yu, Da-hua Wu, Annual Report on Talent Development of Guizhou (2013). Beijing: Social Science Document Press. 2014.03: 12 .

[5] Jinqian Online Website. Play Talent Strengthen Province Strategy times strong voice: Interpretation of Guizhou Province's Middle \& Long Term Development Plan Outline (2010-2020). http://gzrb.gog.com.cn/system/2010/12/23/010980055.shtml.201 0.12 .23 .

[6] Hong-Tie Luo. SouthWest Minority Area Talent Resource Development Research. Chongqing: South West Normal
University Press. 2011.09: 194-200.

[7] Guizhou Provincial Erhnic and Religious Affairs Commission Website. Guizhou "the Twelfth Five" National Development Plan.

http://www.gzmw.gov.cn/News/20130202/20130202_2619_1.ht m.2013.02.2:22-23

[8] Ministry of Education. Name List of Institution of Higher Education Approved and Newly Approved by the Ministry of Education.http://www.moe.gov.cn/publicfiles/business/htmlfiles/ moe/moe_229/201306/153565.html.2013.06.21.

[9] Minoriy Education Section of Education Department in Guizhou. Education Institution. http://mbjyc.gzsedu.cn/Category_998/Index.aspx.2012.05.

[10] Ministry of Education. Notice about "Common University Undergraduate Professional Directory (2012)" and "Common University Undergraduate Profession's Setting Administration Provision". 2012.09.

[11] Guizhou University of F\&E Website. General Situation. http://portal.gzife.edu.cn/web/2013/.2014.04.26. 